\title{
Carbon-coated Aluminum Foil as Current Collector for Improving the Performance of Lithium Sulfur Batteries
}

\author{
Tao Li ${ }^{1,2}$, Hong Bo ${ }^{1,3, *}$, Huawei Cao ${ }^{2}$,Yanqing Lai ${ }^{1}$, Yexiang Liu ${ }^{1}$ \\ ${ }^{1}$ School of Metallurgy and Environment, Central South University, Changsha, Hunan 410083, China \\ ${ }^{2}$ Shenzhen Perfect Power Technology Co.,Ltd, Shenzhen, Guangdong 518057, China \\ ${ }^{3}$ School of Materials Science and Engineering, Central South University, Changsha, Hunan 410083, \\ China \\ *E-mail: bop_hong@163.com
}

doi: $10.20964 / 2017.04 .20$

Received: 23 November 2016 / Accepted: 7 Febuary 2017 / Published: 12 March 2017

\begin{abstract}
Carbon-coated aluminum (Al) foil was employed as a current collector of sulfur cathode in lithium sulfur (Li-S) battery. The physical properties of different foils and prepared electrodes were characterized, and the effects of foil type on the electrochemical performance of the cell were investigated. The artificially designed carbon coating on Al foil enhances the adhesion of active material to the current collector, and reduces electrical resistivity of the sulfur electrode. When using carbon-coated $\mathrm{Al}$ foil, the electrochemical polarization of Li-S cell is obviously diminished and stable potential plateau can be held. Compared to common bare foil, the carbon-coated foil favors more sulfur utilization and better cycle capability. Especially the carbon-coated foil with a point-plane combined surface framework (DC foil) is preferable for the improvement of electrode properties and cell performance than that covered by merely carbon particle material. A high reversible capacity of $655 \mathrm{mAh} \mathrm{g}^{-1}$ after 50 cycles is exhibited in the cell using DC foil, with low charge-transfer resistance.
\end{abstract}

Keywords: carbon-coated aluminum foil; current collector; sulfur cathode; lithium sulfur battery; electrochemical performance

\section{FULL TEXT}

(C) 2017 The Authors. Published by ESG (www.electrochemsci.org). This article is an open access article distributed under the terms and conditions of the Creative Commons Attribution license (http://creativecommons.org/licenses/by/4.0/). 